\title{
Genetic Analysis of Lipase Low-producing Mutants of Yarrowia lipolytica
}

\author{
By B. H. NGA, ${ }^{*}$ C. M. GAILLARDIN, ${ }^{2}$ P. FOURNIER ${ }^{2}$ AND \\ H. HESLOT ${ }^{2}$ \\ ${ }^{1}$ Department of Microbiology, Faculty of Medicine, National University of Singapore, Lower \\ Kent Ridge Road, Singapore 0511, Republic of Singapore \\ ${ }^{2}$ Laboratoire de Génétique des Microorganismes, Centre de Biotechnologie Agro-Industrielle, \\ Institut Agronomique, 78850 Thiverval Grignon, France
}

(Received 15 December 1988; revised 20 April 1989; accepted 31 May 1989)

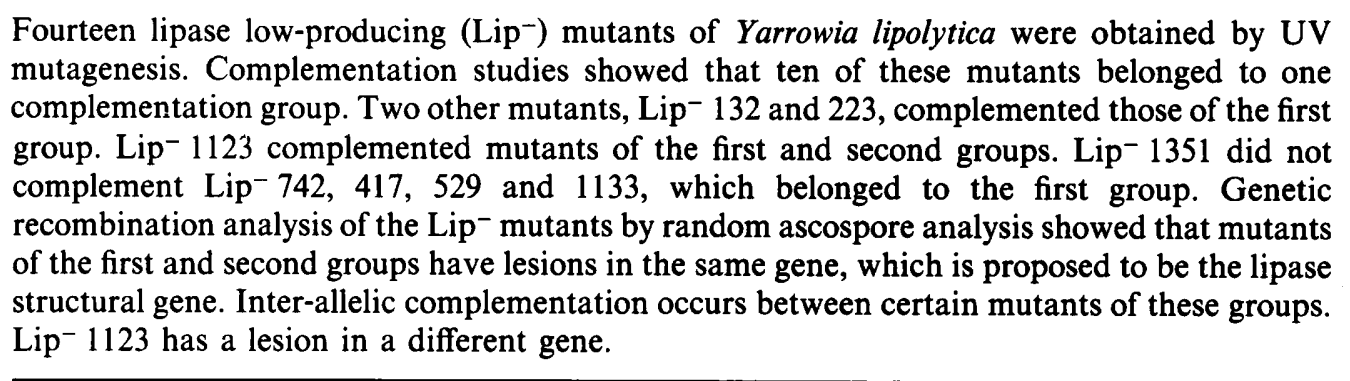

\section{INTRODUCTION}

Yarrowia lipolytica is a dimorphic yeast. Its alkane utilization, lysine metabolism and ability to secrete an alkaline protease and several acid proteases have been studied (Ogrydziak \& Scharf, 1982; Ogrydziak et al., 1982). DNA-mediated transformation systems for this yeast have been studied extensively by Davidow et al. $(1985,1987)$ and Gaillardin et al. (1985). Lipases, which hydrolyse triglycerides, have been isolated and purified from Y. lipolytica (Ota et al., 1978, 1982). Ota et al. (1982) showed that $Y$. lipolytica produced an extracellular lipase and two cell-bound lipases.

Lipases are potentially of use in the palm-oil-based industries of Southeast Asia, for the hydrolysis of triglycerides, transesterification and the production of esters. In 1986, Malaysia produced 4.5 million tonnes of palm oil (Palm Oil Research Institute of Malaysia, 1986). To assist in understanding the genetic control of lipase biosynthesis in $Y$. lipolytica we isolated fourteen lipase low-producing mutants. We describe here the genetic analysis of these mutants.

\section{METHODS}

Strains of Yarrowia lipolytica. Strains A his1 and B leu2 adel xpr 2 were from the collection of H. Heslot. Culture conditions and media. Complex YEPD medium consisted of $1 \%(\mathrm{w} / \mathrm{v})$ peptone, $2 \%(\mathrm{w} / \mathrm{v})$ glucose and $1 \%$ $(w / v)$ yeast extract. Difco Yeast Nitrogen Base (without amino acids) (YNB) was used as minimal medium. Supplementation of this medium when required was as follows: $2 \%(\mathrm{w} / \mathrm{v})$ glucose, $1 \%(\mathrm{w} / \mathrm{v})$ tributyrin, $100 \mathrm{mg}$ each of histidine and leucine $\mathrm{l}^{-1}$ and $50 \mathrm{mg}$ adenine $\mathrm{1}^{-1}$.

Mutagenesis. This was done by UV irradiation of cells of strain A his 1 from agar medium, suspended in $3 \mathrm{ml}$ distilled water at about $5 \times 10^{7}$ cells $\mathrm{ml}^{-1}$, giving 15-20\% survival. Lipase low-producing (Lip ${ }^{-}$) mutants were selected by the nystatin procedure (Snow, 1966; Beckerich et al., 1984). After UV treatment the cells were incubated in YEPD overnight at $28^{\circ} \mathrm{C}$ with shaking. The cultures were harvested by centrifugation $(3000 \mathrm{~g}$, $5 \mathrm{~min}$ ), resuspended in YNB medium containing glucose and incubated for $8 \mathrm{~h}$ for the starvation phase. The medium was then supplemented with $100 \mathrm{mg}$ histidine $1^{-1}, 10 \mathrm{mg}$ tributyrin $\mathrm{l}^{-1}$ and $50 \mathrm{mg}$ yeast extract $\mathrm{l}^{-1}$ and incubated for $6 \mathrm{~h}$. Nystatin and dimethyl sulphoxide were then added to give final concentrations of $10 \mathrm{mg} \mathrm{l}^{-1}$ and $1 \%(\mathrm{w} / \mathrm{v})$ respectively and the culture incubated for $5 \mathrm{~h}$. 
Screening for Lip ${ }^{-}$mutants. Colonies on YEPD plates were inoculated onto YNB supplemented with glucose and histidine. These colonies were then replica plated onto YNB medium supplemented with tributyrin and histidine. Lip- mutants were not able to utilize tributyrin as the sole carbon source and were unable to grow on this medium.

Genetic studies and determination of mating type. Each of the A his $1 \mathrm{Lip}^{-}$mutants was crossed with the haploid strain B leu2 ade 1 xpr2, using the method of Gaillardin et al. (1973). The resulting diploid strains were induced to sporulate (Barth \& Weber, 1985), and ascospores were obtained by treating asci with cytohelicase (LKB) at $30 \mathrm{mg}$ $\mathrm{ml}^{-1}$ and cysteine at $2 \mathrm{mg} \mathrm{ml}^{-1}$ in water for $4 \mathrm{~h}$ at $30^{\circ} \mathrm{C}$ followed by sonication. Colonies grown from single ascospores were plated onto YEPD and subsequently replica-plated onto classification media to isolate haploid strains which were leucine-requiring and Lip $^{-}$.

The leucine-requiring, Lip- haploid strains were tested for mating with the haploid strain A his1. Prototrophic diploid strains were obtained when the $\mathrm{Leu}^{-}$haploids were of $\mathrm{B}$ mating type.

Complementation studies. Diploid strains were obtained from crosses between specific A his 1 Lip $^{-}$haploid strains and B leu2 $\mathrm{Lip}^{-}$strains as above. These were replica-plated onto YNB medium supplemented with tributyrin to test for complementation between the Lip- mutants.

Assay of extracellular lipase activity. The method used was that of Ota \& Yamada (1967). To a mixture of $2 \mathrm{ml}$ lipase assay buffer $(0.2 \mathrm{M}$-Tris/ $\mathrm{HCl}, 0.2 \mathrm{M}$-maleic acid, $0.2 \mathrm{M}-\mathrm{NaOH}$, adjusted to $\mathrm{pH} 8 \cdot 2)$, 1 ml sodium taurocholate $(0.2 \%, \mathrm{w} / \mathrm{v})$ and $1 \mathrm{ml}$ distilled water in an Erlenmeyer flask was added $5 \mathrm{ml}$ polyvinyl alcohol emulsion containing $0.5 \mathrm{ml}$ tributyrin. After incubation at $37^{\circ} \mathrm{C}$ for $10 \mathrm{~min}, 1 \mathrm{ml}$ of the supernatant from a YEPD culture of the test strain which had been incubated for $30 \mathrm{~h}$ at $28^{\circ} \mathrm{C}$ was added. The mixture was incubated for $2 \mathrm{~h}$ with shaking, then the reaction was stopped by adding $20 \mathrm{ml}$ acetone/ethanol $(1: 1, \mathrm{v} / \mathrm{v})$. This was then titrated against $0.05 \mathrm{M}$ sodium hydroxide with phenolphthalein as indicator. A blank was shaken with enzyme which was added immediately before titration, the reaction being stopped instantly. The titration value of the sample was corrected by subtracting the titration value of the blank sample from that of the corresponding test sample. Lipase activity was determined in lipase units. One lipase unit was defined as the amount of enzyme which liberated one microequivalent of free fatty acid per minute.

Strains were also assayed for extracellular lipase activity after growth in YEPD containing $1 \%(\mathrm{v} / \mathrm{v})$ olive oil (Sigma). The lipase assay mixture in this case contained $0.5 \mathrm{ml}$ olive oil instead of tributyrin.

Determination of cell dry weight. A $10 \mathrm{ml}$ sample of an overnight culture was centrifuged in a pre-weighed screwcapped test tube. The pellet was dried to constant weight at $100^{\circ} \mathrm{C}$.

Reversion of Lip ${ }^{-}$mutants. Lip ${ }^{-}$mutants of strain A his 1 were inoculated onto YEPD agar and incubated for $3 \mathrm{~d}$ at either $28{ }^{\circ} \mathrm{C}$ or $16{ }^{\circ} \mathrm{C}$. Cells from these cultures were suspended in $0.9 \%(w / v)$ saline, washed once in saline and resuspended in saline after centrifugation. Samples $(0.1 \mathrm{ml})$ were then spread onto YNB supplemented with tributyrin and histidine and incubated at either $28^{\circ} \mathrm{C}$ or $16^{\circ} \mathrm{C}$ for $5 \mathrm{~d}$. Lip ${ }^{+}$revertants were isolated from this medium and supernatants from cultures of these strains were assayed for lipase activity.

Test for temperature-sensitive lipase of revertants. Lip ${ }^{+}$revertants from $\mathrm{Lip}^{-}$mutants were inoculated into two sets of flasks containing YEPD, incubated overnight at $28^{\circ} \mathrm{C}$ for one set and $16^{\circ} \mathrm{C}$ for the other. Samples of $1 \mathrm{ml}$ of culture supernatant were used for assay for lipase activity at both $28^{\circ} \mathrm{C}$ and $16^{\circ} \mathrm{C}$, with a reaction time of $2 \mathrm{~h}$.

\section{RESULTS AND DISCUSSION}

\section{Characterization of Lip- mutants}

Fourteen A his $1 \mathrm{Lip}^{-}$strains isolated as described in Methods and grown on unsupplemented YEPD medium were assayed for extracellular lipase activity with tributyrin as substrate (Table 1). All the mutants had low lipase activity, ranging from $0 \%$ to $4.2 \%$ of that of the control strain, A his 1. Lip ${ }^{-}$mutants 742, 1362, 936, 108 and 1324 were devoid of lipase activity in tests with olive oil as substrate, using samples of cultures grown in YEPD with olive oil (the other mutants were not tested). Lipase activity for A his 1 was 11.4 units (mg dry wt) $)^{-1}$ under these conditions. In the case of samples from unsupplemented YEPD cultures, strain A his 1 and mutant 742 gave lipase activities of 7 units (mg dry wt) $)^{-1}$ with olive oil as substrate, and mutants $1362,936,108$ and 1324 showed activity of about 3.0 units (mg dry wt) $)^{-1}$.

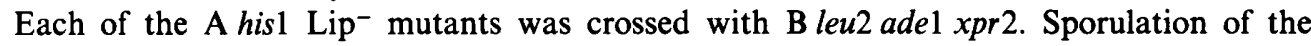
resulting diploid strains gave ascospores which were plated onto YEPD media. Leucinerequiring Lip- haploids corresponding to each of the 14 A his $\mathrm{Lip}^{-}$mutants were obtained. Confirmation of the B leu 2 character of these Lip- haploid strains was achieved by mating with strain A hisl.

The mutations in all $14 \mathrm{Lip}^{-}$strains were recessive, as the diploids formed between each of them and B leu2 ade 1 xpr 2 were Lip ${ }^{+}$. Analysis of the colonies derived from ascospores of these 


\section{Table 1. Lipase activities of Lip- mutants}

All the experiments were performed at least three times and the results presented are means. Standard deviation was less than $10 \%$ of the given figures except in the case of Lip- strain 1123 , for which the standard deviation was $18 \%$ of 2.6 . The lipase activity of the control strain, A his 1 , taken as $100 \%$, was 298 units (mg dry wt) ${ }^{-1}$.

\begin{tabular}{|c|c|c|c|}
\hline $\begin{array}{l}\text { A his } 1 \text { Lip }^{-} \\
\text {strain }\end{array}$ & $\begin{array}{c}\text { Lipase } \\
\text { activity* }\end{array}$ & $\begin{array}{l}\text { A hisl Lip } \\
\text { strain }\end{array}$ & $\begin{array}{c}\text { Lipase } \\
\text { activity* }\end{array}$ \\
\hline 742 & $0 \quad(0 \%)$ & 1133 & $2.9(1.0 \%)$ \\
\hline 1362 & $12 \cdot 8(4.2 \%)$ & 350 & $6.6(2.2 \%)$ \\
\hline 936 & $0 \quad(0 \%)$ & 1432 & $0 \quad(0 \%)$ \\
\hline 108 & $0 \quad(0 \%)$ & 132 & $0 \quad(0 \%)$ \\
\hline 417 & $10.6(3.6 \%)$ & 223 & $6.6(2.2 \%)$ \\
\hline 1324 & $3.5(1.2 \%)$ & 1351 & $3.5(1.2 \%)$ \\
\hline 529 & $6.6(2.2 \%)$ & 1123 & $2.6(0.9 \%)$ \\
\hline
\end{tabular}

* The results are expressed as units (mg dry wt) ${ }^{-1}$; the values in parentheses represent the percentage of control activity.

\section{Table 2. Complementation tests between lipase low-producing mutants}

Eight A his1 Lip- strains, 742, 1362, 936, 108, 417, 1324, 529 and 1133, were crossed with each of the corresponding eight B leu $2 \mathrm{Lip}^{-}$strains, and the resulting diploid strains were replica-plated onto YNB medium plus tributyrin to test for complementation. No complementation occurred. Lipase activities were measured for certain other diploid strains, as shown below.

$\begin{array}{cc}\begin{array}{c}\text { Diploid: } \\ \text { A his1 Lip }\end{array} \text { /B leu2 Lip } & \begin{array}{c}\text { Lipase activity } \\ \text { [units (mg dry wt) }\end{array} \\ 417 / 1324 & 26 \\ 742 / 1432 & 22 \\ 529 / 132 & 182 \\ 1324 / 132 & 171 \\ 223 / 132 & 21 \\ 132 / 1123 & 238 \\ 1324 / 1123 & 252 \\ \text { A hisl Lip } / \text { B leu2 } \text { Lip }^{+} & 316\end{array}$

diploids showed that each gave a 1:1 pattern of segregation for $\mathrm{Lip}^{+}: \mathrm{Lip}^{-}$. This result indicated that the mutation in the $\mathrm{Lip}^{-}$strains was chromosomal and monogenic.

\section{Complementation analysis}

Eight of the A his1 Lip ${ }^{-}$mutants, 742, 1362, 936, 108, 417, 1324, 529 and 1133, were crossed with each of the eight corresponding B leu $2 \mathrm{Lip}^{-}$strains to obtain diploid strains. Diploid strains obtained from these crosses, tested for complementation on YNB medium containing tributyrin, showed that these eight Lip- mutants belonged to one complementation group (see Table 2). Diploid strains obtained from crosses between the B leu2 Lip- strains 350 and 1432 and each of the above A hisl Lip' strains showed that Lip- 350 and 1432 did not complement these eight mutants. Lip ${ }^{-1351}$ did not complement Lip- 742, 417, 529 and 1133. B leu2 Lip ${ }^{-132,223}$ and 1123 complemented A hisl Lip- 936, 1324 and 529. The diploid strain A his1 Lip ${ }^{+} / \mathrm{B}$ leu2 $\mathrm{Lip}^{+}$and those constructed between B leu2 Lip 1123 and each of A his1 Lip- 936, 1324 and 529 were able to grow on YNB containing tributyrin and had a distinctly faster growth rate on this medium than the diploids formed between B leu2 Lip- strains 132 and 223 and the same A his 1 Lip $^{-}$strains. Lip ${ }^{-} 132$ did not complement Lip $^{-}$223. Lip- 1123 complemented Lip ${ }^{-} 132$ and 223.

\section{Genetic recombination analysis}

In order to determine if the $\mathrm{Lip}^{-}$mutants had lesions in the same gene, genetic recombination studies using random ascospore analysis were carried out for the crosses shown in Table 3. 
Table 3. Genetic recombination analysis of Lip- mutants

\begin{tabular}{|c|c|c|c|c|c|c|}
\hline \multirow{3}{*}{$\begin{array}{c}\text { Diploid: } \\
\text { A his1 Lip-/B leu2 Lip }\end{array}$} & \multicolumn{6}{|c|}{ Ascospore colonies of diploid strains } \\
\hline & \multirow[b]{2}{*}{ His $^{-}$} & \multicolumn{2}{|c|}{$\begin{array}{l}\text { Ability to grow on YNB } \\
\text { medium plus histidine } \\
\text { and tributyrin }\end{array}$} & \multirow[b]{2}{*}{$\mathrm{Leu}^{-}$} & \multicolumn{2}{|c|}{$\begin{array}{l}\text { Ability to grow on YNB } \\
\text { medium plus leucine } \\
\text { and tributyrin }\end{array}$} \\
\hline & & + & - & & + & - \\
\hline $417 / 1324$ & 12 & 0 & 12 & 9 & 0 & 9 \\
\hline $529 / 1432$ & 13 & 0 & 13 & 8 & 0 & 8 \\
\hline $529 / 132$ & 16 & 0 & 16 & 9 & 0 & 9 \\
\hline $936 / 1133$ & 14 & 0 & 14 & 12 & 0 & 12 \\
\hline $742 / 1123$ & 19 & 5 & 14 & 13 & 3 & 10 \\
\hline $529 / 1123$ & 16 & 4 & 12 & 11 & 3 & 8 \\
\hline
\end{tabular}

Leucine- and histidine-requiring colonies from ascospores of each of the diploids were tested for their ability to grow on YNB medium supplemented with tributyrin. The ascospore-derived colonies from each of the A his 1 Lip-/B leu2 Lip- diploids 417/1324, 529/1432, 529/132, 936/1133, 742/1123 and 529/1123 were inoculated onto YNB medium containing histidine or leucine and tributyrin. Except for the colonies from the 1123 diploids, all the histidine- and leucine-requiring colonies were unable to grow on appropriately supplemented YNB media with tributyrin. The diploid 742/1123 gave $14 \mathrm{His}^{-}$colonies which were $\mathrm{Lip}^{-}$and 5 which were $\mathrm{Lip}^{+}$; diploid 529/1123 gave 12 colonies which were $\mathrm{Lip}^{-}$and 4 which were $\mathrm{Lip}^{+}$. Leucine-requiring colonies from these diploids also gave a ratio of $\mathrm{Lip}^{-}: \mathrm{Lip}^{+}$colonies of close to $3: 1$. When considered together, these results and those of the complementation studies showed that the Lip - mutants 742, 1362, 936, 108, 417, 1324, 529, 1133, 350 and 1432 had lesions in one lipase gene, that mutants 132 and 223 had lesions in the same gene and inter-allelic complementation occurred between 132 and 223 on the one hand and 936, 1324 and 529 on the other. Lip- 1123 had a lesion in a different gene affecting lipase production.

\section{Reversion studies of Lip- mutants}

To establish whether the Lip ${ }^{-}$mutants had lesions in the putative structural gene for lipase in $Y$. lipolytica, spontaneous revertants of the A his 1 Lip $^{-}$mutants $1362,108,223,1324,350,1432$ and 1123 were obtained to determine the temperature sensitivity of their extracellular lipase. The results are shown in Table 4 (the samples for lipase assay were from cultures grown at $28^{\circ} \mathrm{C}$ ). Except for strain Lip $^{-} 1123$, all the mutants gave a number of revertants with temperature-sensitive lipase. We conclude that these mutants are affected in the lipase structural gene. No temperature-sensitive lipase was obtained from $\mathrm{Lip}^{+}$revertants of mutant 1123 in a total of 102 revertants assayed, suggesting that in this mutant the lesion might have affected a different gene, perhaps one of the genes responsible for the secretion of lipase.

Ota et al. (1973) described an extracellular lipase which required activator A from culture supernatant of $Y$. lipolytica or an unsaturated fatty acid like oleic acid (Ota \& Yamada, 1967) for its lipolytic activity at pH 7.0 in an unemulsified shaken reaction system. Sugiura et al. (1976) reported that cell-bound lipase was active without the addition of an activator. The latter authors also showed that cell-bound lipase and extracellular lipase had an optimum $\mathrm{pH}$ of 8.0 when olive oil was the substrate. The optimum $\mathrm{pH}$ for cell-bound lipase was 7.0 with tributyrin as the substrate, while extracellular lipase hydrolysed tributyrin most effectively at $\mathrm{pH} 8.2$ in the presence of oleic acid. Ota et al. (1982) reported the isolation of two cell-bound lipases and an extracellular lipase. They suggested, from a study of the enzymological properties of cell-bound lipases I and II, that one enzyme was probably a modified form of the other. According to Ota et al. (1982), cells grown in the absence of lipid produced lipase which hydrolysed tributyrin but not olive oil. In the present study, cells grown in YEPD without olive oil produced lipase which hydrolysed both tributyrin and olive oil. In the presence of olive oil, $Y$. lipolytica produced an extracellular lipase which hydrolysed olive oil. It seems possible that the $\mathrm{Lip}^{-}$mutants have 
Table 4. Lipase activities of revertants of Lip $^{-}$mutants

$\begin{array}{ccccc}\begin{array}{c}\text { A his } \text { Lip }^{-} \\ \text {strain }\end{array} & \begin{array}{c}\text { No. of Lip } \\ \text { revertants }\end{array} & \begin{array}{c}\text { No. of } \\ \text { temperature-sensitive } \\ \text { revertants }\end{array} & \begin{array}{c}\text { Temperature-sensitive } \\ \text { revertants }\end{array} & \begin{array}{c}\text { Other } \\ \text { revertants } \dagger\end{array} \\ 1362 & 76 & 3 & 0.3 & 0.7-1(11) \\ 108 & 81 & 3 & 0.3 & 0.7-1(5) \\ 223 & 74 & 3 & 0 \cdot 25 & 0.75-1(11) \\ 1324 & 79 & 2 & 0.33 & 0.66-1(8) \\ 350 & 80 & 2 & 0.33 & 0.8-1(6) \\ 1432 & 75 & 2 & 0.27 & 0.7-1(12) \\ 1123 & 102 & 0 & & 0.7-1(14)\end{array}$

* Samples for lipase assay were from YEPD cultures incubated at $28^{\circ} \mathrm{C}$.

+ The number of revertants tested is shown in parentheses.

lesions that affect the gene for lipase which hydrolyses both tributyrin and olive oil, but at different levels of activity.

B.H.N. wishes to acknowledge financial support from the Singapore Council under the Research and Development Assistance Scheme. He is also grateful to the French Government for the Academic Exchange Award which enabled him to spend a sabbatical in the laboratory of Professor Henri Heslot in 1986. The authors are grateful to Mrs Caroline Riddett for assistance in the preparation of the manuscript.

\section{REFERENCES}

BARTH, G. \& WEBER, H. (1985). Improvement of sporulation in the yeast Yarrowia lipolytica. Antonie van Leeuwenhoek 51, 167-177.

Beckerich, J. M., Ceccaldi, B. C., Lambert, M. \& HesLot, H. (1984). Evidence for the control of a mutation in lysine catabolism by the mating type in Yarrowia lipolytica. Current Genetics 8, 531536.

Davidow, L. S., Apostolakos, D., O’Donnell, M. M., Proctor, A. R., Ogrydziak, D., Wing, R. A., Stasko, I. \& De Zeeuw, J. R. (1985). Integrative transformation of the yeast Yarrowia lipolytica. Current Genetics 10, 39-48.

Davidow, L. S., O'DonNell, M. D., KaCMAREK, F. S., Pereira, D. A., De Zeeuw, J. R. \& Franke, A. E. (1987). Cloning and sequencing of the alkaline extracellular protease gene of Yarrowia lipolytica. Journal of Bacteriology 169, 4621-4629.

Gaillardin, C. M., Charoy, V. \& Heslot, H. (1973). A study of copulation, sporulation and meiotic segregation in Candida lipolytica. Archives of Microbiology 92, 69-83.

Gaillardin, C. M., Ribet, A. M. \& Heslot, H. (1985). Integrative transformation of the yeast Yarrowia lipolytica. Current Genetics 10, 49-58.

OgrydziaK, D. M. \& ScharF, S. J. (1982). Alkaline extracellular protease produced by Saccharomycopsis lipolytica CX 161-1B. Journal of General Microbiology 128, 1225-1234.

OGRYdZIAK, D. M., BASSEL, J. \& MORTIMER, R. (1982). Development of the genetic map of the yeast
Yarrowia lipolytica. Molecular and General Genetics 188, 179-183.

OTA, Y. \& YamadA, K. (1967). Lipase from Candida paralipolytica. Part III. Further studies on the activation of the enzyme. Agricultural and Biological Chemistry 31, 809-816.

Ota, Y., Yoshioka, K., Minoda, Y. \& Yamada, K. (1973). Demonstration of lipid lipase activators produced by Candida paralipolytica. Agricultural and Biological Chemistry 37, 2879-2883.

OtA, Y., Morimoto, Y., Sugiura, T. \& Minoda, Y. (1978). Soybean fraction increasing the extracellular lipase production by Saccharomycopsis lipolytica (Candida paralipolytica). Agricultural and Biological Chemistry 42, 1937-1938.

Ota, Y., Gomi, K., Kato, S., SugiJRA, T. \& Minoda, Y. (1982). Purification and some properties of cellbound lipase from Saccharomycopsis lipolytica. Agricultural and Biological Chemistry 46, 2885-2893.

Palm Oil Research Institute of Malaysia (1986). Data Sheet I. Palm Oil.

SNow, R. (1966). An enrichment method for auxotrophic yeast mutants using the antibiotic 'nystatin'. Nature, London 211, 206-207.

Sugiura, T., Ota, Y. \& Yamada, K. (1976). Partial characterisation of cell-bound lipase of Candida paralipolytica. Agricultural and Biological Chemistry 40, 2479-2480. 